\title{
Structural and functional analysis of virus factories purified from Rabbit vesivirus-infected Vero cells
}

\author{
Rosa Casais ${ }^{a}$, Lorenzo González Molleda ${ }^{b}$, Angeles Machín $^{\mathrm{b}}$, Gloria del Barrio $^{\mathrm{b}}$, \\ Alberto García Manso ${ }^{b}$, Kevin P. Dalton ${ }^{b}$, Ana Coto ${ }^{c}$, José Manuel Martín Alonso ${ }^{b}$, \\ Miguel Prieto ${ }^{a}$, Francisco Parra ${ }^{\mathrm{b}, *}$ \\ a Servicio Regional de Investigación y Desarrollo Agroalimentario (SERIDA), Laboratorio de Sanidad Animal, Jove del Medio, Gijón, Asturias, Spain \\ b Departamento de Bioquímica y Biología Molecular, Instituto Universitario de Biotecnología de Asturias, Universidad de Oviedo, Oviedo, Spain

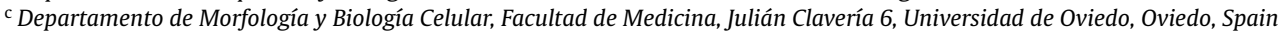

\section{A R T I C L E I N F O}

\section{Article history:}

Received 14 April 2008

Received in revised form 17 June 2008

Accepted 17 June 2008

Available online 26 July 2008

\section{Keywords:}

Caliciviridae

Rabbit vesivirus

Replication complex

Virus factories

\begin{abstract}
A B S T R A C T
Rabbit vesivirus infection induces membrane modifications and accumulation of vesicular structures in the cytoplasm of infected Vero cells. Crude RaV replication complexes (RCs) have been purified and their structural and functional properties have been characterized. We show that calnexin, an ER-resident protein, $\mathrm{RaV}$ non-structural proteins 2AB-, 2C-, 3A-, 3B- and 3CD-like as well as viral RNAs co-localize within membranous structures which are able to replicate the endogenous RNA templates. The purified virus factories protected their viral RNA contents from microccocal nuclease degradation and were inaccessible to exogenously added synthetic transcripts. In addition, we have shown that RCs can be used to investigate uridylylation of native endogenous VPg. In contrast to the observation that the virus factories were inaccessible to RNAs, RCs were accessible to added recombinant VPg which was subsequently nucleotidylylated. Nevertheless no elongation of an RNA chain attached to native or recombinant VPg could be demonstrated.
\end{abstract}

(c) 2008 Elsevier B.V. All rights reserved.

\section{Introduction}

Rabbit vesivirus ( $\mathrm{RaV}$ ), has been recently characterized as a putative new member of the genus Vesivirus within the family Caliciviridae (Martin-Alonso et al., 2005). The virus genome, a single-stranded positive-sense RNA of about $8.3 \mathrm{~kb}$ in length, is covalently linked at its $5^{\prime}$-terminus to a small virus protein (VPg) and is polyadenylated at its $3^{\prime}$-end. Analysis of the RaV genome sequence indicates the presence of three ORFs, similar to those described for Vesivirus and Norovirus (Clarke and Lambden, 1997; Green, 2007). ORF1 encodes a polyprotein of 1880 amino acids including domains homologous to the picornavirus non-structural proteins 2C (helicase-NTPase, residues 590-597 for the GxxGxGKT motif), 3C (cysteine protease, residues 1303-1308 for the motif containing the catalytic cysteine), and 3D (RNAdependent RNA polymerase, residues $1598-1603$ for motif $A$, or 1701-1704 for motif C). ORF2 encodes a 705-residue protein (Mr.

\footnotetext{
* Corresponding author at: Departamento de Bioquímica y Biología Molecular, Edificio Santiago Gascón, Campus El Cristo, 33006 Oviedo, Spain.

Tel.: +34 985 103563; fax: +34985103157.

E-mail address: fparra@uniovi.es (F. Parra).
}

$78,701)$, a precursor of the mature capsid protein as deduced from the observed $67 \mathrm{kDa}$ molecular mass of the major structural protein found in purified virions. ORF3 encodes a 110-residue protein possibly corresponding to a minor structural component of the virion as described for Feline calicivirus (FCV) (Herbert et al., 1996; Sosnovtsev and Green, 2000), Rabbit hemorrhagic disease virus (RHDV) (Wirblich et al., 1996) and Norwalk virus (Glass et al., 2000). A distinctive feature of the vesiviruses is the presence of a protease-polymerase bifunctional $3 \mathrm{CD}$-like protein, which is not further processed to 3C-and 3D-like mature products (Sosnovtseva et al., 1999).

Replication of positive-stranded RNA viruses occurs in membrane-bound replication complexes (RCs) composed of viral and cellular proteins and viral RNA. However, different RNA viruses target distinct membranes and form different membrane structures (El-Hage and Luo, 2003; Prentice et al., 2004; Schaad et al., 1997; Suhy et al., 2000; Westaway et al., 1997, 1999) possibly indicating specific requirements for viral replication.

The study of the replication strategies of several human and animal caliciviruses has been frequently hampered by the lack of suitable cell culture and reverse genetic systems for these viruses. The isolation and characterization of enzymatically active RCs (Green et al., 2002) has opened new perspectives for the study of 
calicivirus replication in a system in which relevant protein-protein interactions could be reasonably preserved (Kaiser et al., 2006). The use of such complexes is a step forward from the extremely simplified conditions, based on purified recombinant proteins, used in most of the published studies addressing calicivirus replication (Belliot et al., 2005; López Vázquez et al., 1998; Machín et al., 2001; Wei et al., 2001) or those based on the use of heterologous hosts (Kaiser et al., 2006).

In order to investigate the replication of $\mathrm{RaV}$, a putative new member of the vesivirus of marine origin, we report in this paper the structural-functional characterization of virus factories from RaV-infected Vero cells.

\section{Materials and methods}

\subsection{Cells and viruses}

Rabbit vesivirus (Martin-Alonso et al., 2005) was propagated using Vero cells cultured in minimum essential medium supplemented with foetal bovine serum (10\%), and antibiotics.

\subsection{Purification of replication complexes}

Membrane-associated viral factories were isolated from RaVinfected cells essentially as described previously (Green et al. 2002). Briefly, Vero cells monolayers in $150 \mathrm{~cm}^{2}$ flasks were infected with RaV at a multiplicity of infection (MOI) of 10 . Cells were harvested by centrifugation $4 \mathrm{~h}$ post-infection (hpi), the resulting sediments were suspended in $1 \mathrm{ml}$ of ice cold TN buffer ( $10 \mathrm{mM}$ Tris [pH 7.8], $10 \mathrm{mM} \mathrm{NaCl}$ ) and homogenized with a Dounce. Intact cells and nuclei in the resulting extract were sedimented by centrifugation, and the supernantant was further centrifuged at $14,500 \mathrm{rpm}$ $(20,800 \mathrm{~g})$ for $20 \mathrm{~min}$ at $4{ }^{\circ} \mathrm{C}$ using a Heraeus Biofuge primoR centrifuge fitted with a 7593 rotor. The crude membrane sediment (which will be referred as P14500) was finally suspended in $120 \mu \mathrm{l}$ ( $1.3 \mu \mathrm{g} \mu \mathrm{l}^{-1}$ of protein) of TN buffer containing $15 \%$ glycerol and stored at $-80^{\circ} \mathrm{C}$ for further use. Similar samples were concurrently obtained from mock-infected Vero monolayers.

\section{3. $R N A$ replication assay}

The procedure used was similar to previously described methods (Bienz et al., 1992; Green et al., 2002) with some modifications. Briefly, $18 \mu \mathrm{l}$ samples of the RaV- or mock-infected P14500 membrane suspensions were added to the reaction mixtures $(50 \mu \mathrm{l}$ final volume) also containing $50 \mathrm{mM}$ HEPES ( $\mathrm{pH} 8.0$ ), $10 \mathrm{mM}$ dithiothreitol, $3 \mathrm{mM} \mathrm{MgCl} 2,0.25 \mathrm{mM}$ GTP, $0.25 \mathrm{mM}$ CTP, $1 \mathrm{mM}$ ATP, $0.25 \mu \mathrm{M}$ UTP [ $\left.\alpha{ }^{32} \mathrm{P}\right] \mathrm{UTP}(800 \mathrm{Ci} / \mathrm{mmol}$, PerkinElmer $), 40 \mu \mathrm{M}$ UTP, $10 \mu \mathrm{g} \mathrm{ml}^{-1}$ actinomycin D, $40 \mathrm{U}$ of RNasin (Promega Corporation, Madison, $\mathrm{WI}$ ), and $50 \mathrm{mM}$ potassium acetate. The reaction mixtures were incubated at $30^{\circ} \mathrm{C}$ for $1 \mathrm{~h}$ and their total RNA content was then purified using a RNeasy Mini Kit (Qiagen, Valencia, CA). The resulting RNA was eluted using $100 \mu$ l of diethyl pyrocarbonate (DEPC)-treated water and further concentrated by precipitation in ethanol at $-20^{\circ} \mathrm{C}$. The RNA sediments were washed with $70 \%$ ethanol, suspended in $15 \mu$ l of RNA electrophoresis loading buffer, denatured for $45 \mathrm{~min}$ at $65^{\circ} \mathrm{C}$, and analysed in $1.0 \%$ agarose-formaldehyde gels. After electrophoresis, the gels were photographed, dried and exposed to X-Omat LS film (Kodak, Rochester, NY). RaV RCs were treated with micrococcal nuclease to remove RNA by incubation $(1.3 \mu \mathrm{g}$ of protein $/ \mu \mathrm{l})$ with $1 \mathrm{unit} / \mu \mathrm{l}$ of the enzyme in the presence of $750 \mu \mathrm{M} \mathrm{CaCl}_{2}$ for $30 \mathrm{~min}$ at $30^{\circ} \mathrm{C}$ after which the reaction was stopped by adding $5 \mathrm{mM}$ EGTA.
Table 1

Oligonucleotides used for analysis of RaV replication complexes

\begin{tabular}{lllll}
\hline Primer & Sequence $\left(5^{\prime}-3^{\prime}\right)$ & Polarity & Position $^{\mathrm{a}}$ & Use $^{\mathrm{b}}$ \\
\hline RaV 24 & GGTGACAAGTGCCCATCGCGA & + & $3992-4012$ & RT \\
RaV 2 & AACTAGTCCGTTTGTAGAAGC & - & $8095-8116$ & RT \\
Gd & CAAAAGACAAGGTCGCAATCG & + & $4595-4615$ & qPCR \\
Gr & ATTGGCCATGATTGATTCTGAAA & - & $4708-4686$ & qPCR \\
GSGd & ACTACTCCCTGCCCCTGACT & + & $7571-7591$ & qPCR \\
GSGr & GAGTGGACGCACCGACGTA & - & $7684-7666$ & qPCR \\
\hline
\end{tabular}

a The oligonucleotide coordinates refer to numbering used in full-length RaV genome sequence (Martin-Alonso et al., 2005), accession number AJ866991.

b RT: reverse transcription; qPCR: quantitative polymerase chain reaction.

\subsection{Quantitative RT-PCR.}

Reverse transcriptase-coupled quantitative real-time PCR (qRTPCR) was used for the specific and sensitive analysis and quantification of RaV genomic and subgenomic RNAs in the purified RCs and RaV virions. RT reactions were done, in all cases, using SuperScript II reverse transcriptase (Invitrogen). The RNA template used as control was a full length RaV gRNA synthetic transcript (1.4 $\mu \mathrm{g}$ per reaction). The problem samples consisted of total RNAs purified from $120 \mu$ l of replication complexes ( $0.6 \mu$ g per reaction) or the RNAs extracted from RaV virions purified through a caesium chloride gradient ( $0.6 \mu \mathrm{g}$ per reaction), using the RNeasy Mini kit. RT reactions used for detection of positive stranded RNAs were primed with oligonucleotide RaV 2 (complementary to residues 8116-8095 of the RaV genome) (Table 1 ). RT reactions designed for detection of RaV-related negative strand RNAs were carried out using primer RaV 24 (residues 3992-4012) (Table 1). qRT-PCRs (Fig. 3 ) for the quantification of RaV genome ( $g+$ RNA) were done using RaV 2-primed RT reactions as the template in the presence of Gd and Gr primers (Table 1) which yielded a specific 113-bp amplicon derived from the 3CD-like coding region. For qRT-PCR reactions designed to detect total $\operatorname{RaV}(+) \mathrm{RNA}$, which included both $\mathrm{g}+\mathrm{RNA}$ and RaV subgenomic messenger ( $\mathrm{sg}+\mathrm{RNA}$ ), primers GSGd and GSGr (Table 1 ) were used yielding a 114-bp amplicon. The amount of sg + RNA was deduced by substracting the $g$ + RNA concentrations from the total (genomic + subgenomic) (+)RNAs. sg RNA amounts were calculated, using a conversion factor of 3.06 (sgRNA is 3.06 times smaller that the gRNA). RaV 24 was used in combination with GSGd and GSGr primers for the detection of negative strand genomic copies. The qPCR was done using the Platinum SYBR Green qPCR Supermix-UDG kit (Invitrogen) and the ABI PRISM 7000 sequence detection system (Applied Biosystems). Two independent standard curves, for each oligonucleotide pair $(\mathrm{Gd} / \mathrm{Gr}$ or GSGd/GSGr) were done. Standard curves were done using 8- serial 10 -fold dilutions of the corresponding RT reaction using the control full length RaV gRNA synthetic transcript. Additional negative control samples were done in the absence of RNA templates or by omission of reverse transcriptase and oligonucleotides in the RT reactions. For control and problem qPCR reactions 10 -fold dilutions of the corresponding RT reactions were used. Master mixtures were made on ice and each reaction was run in triplicate. The reaction mix contained the Platinum ${ }^{\circledR}$ SYBR $^{\circledR}$ Green qPCR SuperMix-UDG and forward and reverse primers for either the $3 C D$ gene or the capsid gene amplification. The PCR program was as follows: $1 \times(5 \mathrm{~min}$ at $\left.95^{\circ} \mathrm{C}\right), 45 \times\left(15 \mathrm{~s}\right.$ at $95^{\circ} \mathrm{C}, 30 \mathrm{~s}$ at $60^{\circ} \mathrm{C}, 40 \mathrm{~s}$ at $\left.72{ }^{\circ} \mathrm{C}\right), 1 \times(1 \mathrm{~min}$ at $\left.60^{\circ} \mathrm{C}\right)$.

\subsection{VPg uridylylation assay}

Uridylylation of $\mathrm{RaV}$ genome-linked protein ( $\mathrm{VPg}$ ) in crude membrane fractions was analysed using a previously described protocol (Machín et al., 2001). Briefly, the reaction (20 $\mu$ l final volume) 
included $50 \mathrm{mM}$ HEPES pH 7.5, $1 \mathrm{mM} \mathrm{MnCl}_{2}, 2 \mu \mathrm{Ci}\left[\alpha^{3}{ }^{32} \mathrm{P}\right]-U T P$ $\left(800 \mathrm{Ci} \mathrm{mmol}^{-1}\right)$, and appropriate amounts of RaV RCs $(15.6 \mu \mathrm{g})$ or exogenously added recombinant VPg $(1.4 \mu \mathrm{g})$. Previous studies from our laboratory using recombinant VPg proteins showed that optimal radioactivity incorporation to VPg was obtained using VPg quantities ranging from 1 to $3 \mu \mathrm{g}$ (data not shown). The reaction mixtures were incubated for $1 \mathrm{~h}$ at $30^{\circ} \mathrm{C}$, stopped by addition of SDS-PAGE loading buffer and analyzed on $15 \%$ polyacrylamide gels, which were finally dried and autoradiographed. $\left[\alpha-{ }^{32} \mathrm{P}\right]-\mathrm{UMP}$ incorporated into the reaction products was quantified using the Bio-Imaging analyser FLA-7000 (FUJIFILM).

\subsection{RaV-specific antisera}

Recombinant proteins including residues 137-202, 507-791, $864-1035,1071-1183,1186-1881$ of RaV ORF1 polyprotein and residues 153-705 of ORF2 were produced in Escherichia coli, purified and used to immunize rabbits to raise specific antisera (R $\alpha 2 A B$, 2C, 3A, VPg, 3CD and mCap) against selected viral products (Fig. 4A). Notice that constructs $2 \mathrm{AB}, 2 \mathrm{C}, 3 \mathrm{~A}$ used to raise antisera encode fragments of the total corresponding predicted products.

\subsection{Replication complex fractionation}

Confluent Vero cell monolayers in $150 \mathrm{~cm}^{2}$ flasks were infected with $\mathrm{RaV}$ at a MOI of 10 . After virus adsorption for $1 \mathrm{~h}$ at $37^{\circ} \mathrm{C}$, the inoculum was removed and the cultures were maintained for a total of $4 \mathrm{~h}$, after which cells were detached and collected by centrifugation. The cell pellets were suspended in $1 \mathrm{ml}$ of hypotonic buffer (20 mM HEPES, pH 7.4, $10 \mathrm{mM} \mathrm{KCl,} 1.5 \mathrm{mM} \mathrm{MgCl}_{2}, 1 \mathrm{mM} \mathrm{DTT}$ ), containing a protease inhibitor cocktail ( 1 tablet $/ 50 \mathrm{ml}$ ) (Complete, EDTA-free (Roche)) and treated as described above for the isolation of RCs. The P14500 sediments were suspended in isotonic buffer ( $35 \mathrm{mM}$ HEPES, pH 7.4, $146 \mathrm{mM} \mathrm{KCl}, 5 \mathrm{mM} \mathrm{MgCl} 2,1 \mathrm{mM}$ DTT containing a protease inhibitor cocktail) up to a final volume of $120 \mu \mathrm{l}$. The RCs were then layered onto a linear density sucrose gradient (10-50\% sucrose) made in isotonic buffer and centrifuged using a Beckman SW60Ti rotor at $150,000 \mathrm{~g}$ for $17 \mathrm{~h}$ at $4{ }^{\circ} \mathrm{C}$. After centrifugation, nine fractions of $480 \mu$ l were collected from top to bottom and the remaining sediment was suspended as well using $480 \mu \mathrm{l}$ of isotonic buffer. To investigate the effects of Nonidet P-40 (NP40) treatment on RC structure the P14500 sediments were treated with $1.0 \% \mathrm{NP}-40$ for $1 \mathrm{~h}$ on ice prior to being analysed on the sucrose gradient.

\subsection{RaV RNA dot-blot}

Detection of viral RNA in sucrose gradient fractions was done using $100 \mu \mathrm{l}$ samples, previously heated for $15 \mathrm{~min}$ at $65^{\circ} \mathrm{C}$, and spotted onto a Duralose-UV membrane (Stratagene) using a dot blot apparatus (BioRad). The membranes were probed with a 1.4-kb Nhel restriction fragment (including nucleotide residues $6450-7860$ of the RaV genome) labelled with Rediprime DNA labelling system (HE Healthcare Life Sciences) in the presence of $\left.{ }^{32} \mathrm{P}\right]$-dCTP (3000 Ci/mmol, GE Healthcare Amersham). One microgram of RNA purified from RaV virions and $1 \mu \mathrm{g}$ of total RNA extracted from uninfected Vero cells were used as controls.

\subsection{SDS-PAGE and Western blot}

Analyses of the RCs (P14500) protein profiles were performed using SDS-polyacrylamide (10-15\%) gels (Laemmli, 1970). After electrophoresis, proteins were transferred onto Immobilon$\mathrm{P}$ (Millipore) according to the manufacturer's recommendations. Membranes were then incubated in 5\% non-fat dried milk in PBS containing $0.1 \%$ Tween 20 (PBS-T) for $30 \mathrm{~min}$ at room temperature. Antigen detection was performed using specific antisera (1:100 in PBS-T) for $1 \mathrm{~h}$ at RT except for anti-VPg serum that was incubated overnight at $4{ }^{\circ} \mathrm{C}$ and $4 \mathrm{~h}$ at room temperature. Membranes were then washed six times for $5 \mathrm{~min}$ with PBS-T. Immunocomplexes were revealed using Protein A or rabbit anti-goat peroxidaseconjugated (1:1500 in PBS-T) for $1 \mathrm{~h}$ at RT. Membranes were then washed and revealed using 4-chloro-1-naftol or chemiluminescence (BM chemiluminescence blotting substrate (POD)) from Roche following the manufacturer's instructions. Polyclonal goat anti-calnexin serum (Santa Cruz Biotechnology, Inc.) raised against a peptide mapping at the C-terminus of calnexin of human origin, was used at 1:100 dilution, and rabbit anti-mCap was used at 1:500 dilution.

\subsection{Indirect immunofluorescence}

For indirect immunofluorescence (IF), Vero cells were cultured and infected on glass coverslips at a MOI of 10 . At 4 hpi the cells were washed with PBS, fixed with $4 \%$ paraformaldehyde, permeabilized with $0.1 \%$ Triton X-100 in PBS and blocked and rehydrated with PBS containing $1 \%$ bovine serum albumin (BSA). For the detection of $\mathrm{RaV}$ proteins, the cell preparations were incubated with the appropriate primary antibody, washed three times with PBS containing $1 \% \mathrm{BSA}$, and incubated with the corresponding antispecies antibody, labelled with fluorescein isothiocyanate (FITC) (Sigma). After three additional washes with PBS containing 1\% BSA and a wash with distilled water, coverslips were mounted in glycerol containing sodium phosphate and citric acid (Sigma) and subsequently sealed with nail varnish. For double-label immunofluorescence incubation with primary antibodies from different species was done simultaneously whereas FITC and Cyanine 5 conjugated secondary antibodies were used sequentially with a washing step in between incubations.

Polyclonal primary antibodies were prepared at the desired dilution in blocking solution and pre-adsorbed overnight at $4{ }^{\circ} \mathrm{C}$ on $4 \%$ formaldehyde-fixed Vero cells prior to their use in the immunofluorescence test to reduce background staining of uninfected Vero cells. The following Ab dilutions were used: rabbit anti-2AB, 2C, 3A, VPg (1:100); anti-3CD (1:80); anti-mCap (1:200); goat anti-calnexin serum (1:50); sheep anti-rabbit antibody coupled to FITC (1:100) and donkey anti-goat coupled to Cyanine 5 (1:75). All immunofluorescence infection and labelling experiments were performed at least three times. Images were acquired using a confocal laser-scanning microscope (Leica TCS-SP2-AOBS) using a $63 \mathrm{X}$ oil-immersion objective. Raw images were adjusted for contrast and background staining with Adobe Photoshop software.

\subsection{Electron microscopy}

For transmission electron microscopy (TEM) mock and RaVinfected cells (MOI of 1 ) were trypsinized at $8 \mathrm{~h}$ post-infection and fixed by immersion in a solution containing $1.5 \%$ glutaraldehyde, $2.5 \%$ paraformaldehyde in phosphate buffer $0.1 \mathrm{M}(\mathrm{pH} 7.4)$ The fixation was prolonged $2 \mathrm{~h}$ in fresh fixative at room temperature. The cell pellet was post-fixed in $1 \% \mathrm{OsO}_{4}$ for $30 \mathrm{~min}$. After dehydration in graded acetone, the pieces were embedded in Taab 812. Ultrathin sections were collected on cooper grids, stained with uranyl acetate-lead citrate and examined with a transmission electron microscope Zeiss EM-109 (Zeiss, Germany) operating at $80 \mathrm{kV}$. Negatives were scanned by hpscanjet 3970, imported by Adobe Photoshop 7.0.1 and incorporated into the figure using Corel Draw 8.0. Notice that the experimental conditions used in the TEM experiments were different from those used for the 
preparation of RaV RCs (cells harvested at 4 hpi using a MOI of $10)$.

\section{Results}

\subsection{Morphological changes induced in Vero cells by RaV infection}

Positive-strand RNA viruses of eukaryotes assemble RNA RCs using intracellular membranes. The EM analysis of RaV-infected Vero cells revealed distinct membrane alterations (Fig. 1B-D) not observed in uninfected cultures (Fig. 1A). RaV infection caused the formation and accumulation of numerous vesicular structures in the cytoplasm of the infected cell (black arrows in Fig. 1B and C) which have also been described in FCV-infected CRFK-cells (Green et al., 2002). Such vesicles were not found in mock-infected cells (Fig. 1A). Some of the vesicles are formed by whorls of membranous material, a typical feature of cellular autophagy (Fig. 1C, black arrowhead), which has been proposed to be a mechanism of RC formation for the positive-sense RNA viruses (Gosert et al., 2002; Pederson, 1999; Schlegel et al., 1996; Suhy et al., 2000). In non-infected cells numerous mitochondria, could be visual- ized (Fig. 1A) whereas in infected Vero cells these organelles were scarce and had a damaged appearance with crystal structures present (Fig. 1C, asterisk). In addition, abundant electron dense bodies could also be found in the proximity of the plasma membrane of infected cells (Fig. 1D, clear arrows) that could correspond to RaV virions although their typical morphology could not be observed due to the low magnification used. In order to investigate the presence of functional RCs associated to such structures we have purified membrane fractions from infected Vero cell cultures.

\subsection{Functional characterization of RaV RCS}

Membrane fractions from mock and RaV-infected Vero cells were isolated at $4 \mathrm{hpi}$ essentially as previously described (Green et al., 2002). In order to investigate whether the isolated membranous sediment (P14500) contained functional RaV RCs we assayed their RNA-dependent RNA polymerase (RdRP) activity in the presence of [ $\left.{ }^{32} \mathrm{P}\right]-$ UTP. The reactions, performed in the absence of added template or primer RNAs, were stopped at $0,10,30$ and 60 min and the
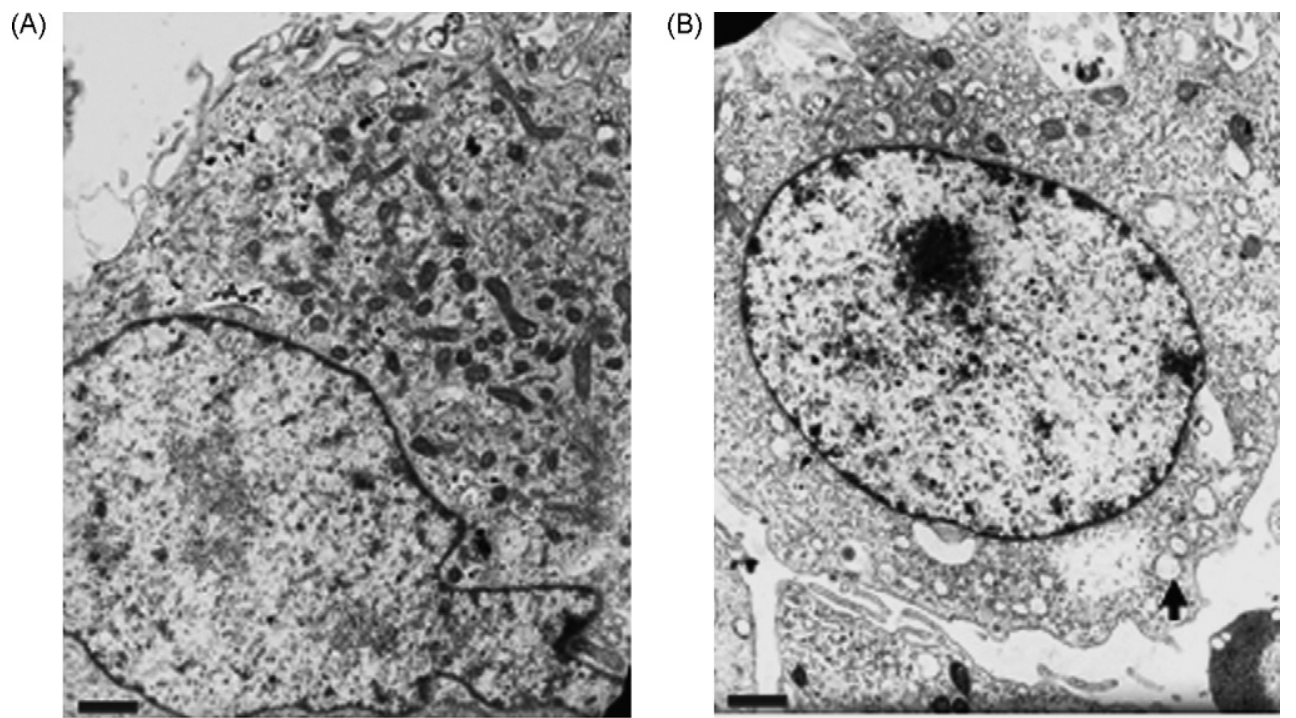

(C)

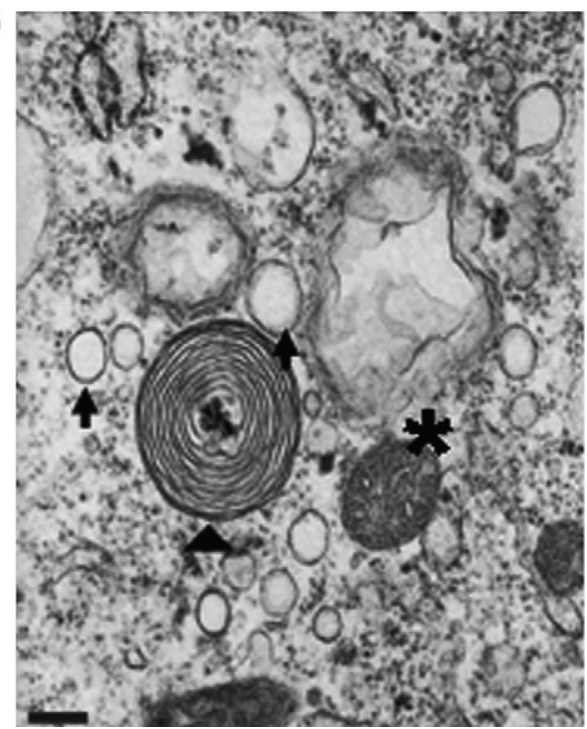

(D)

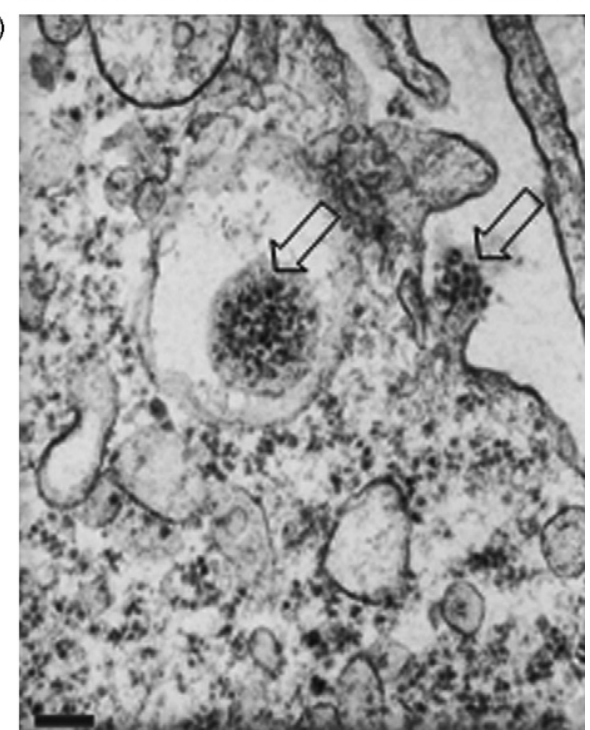

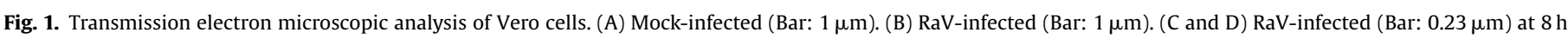

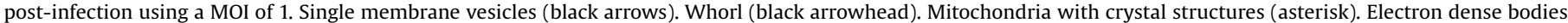
(clear arrows). 


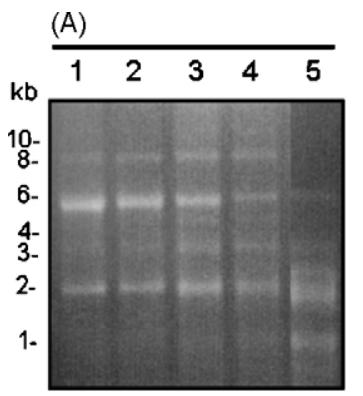

(B)

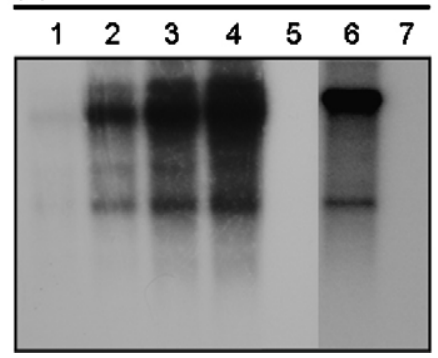

(C)

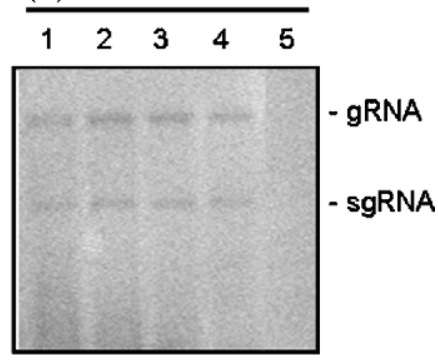

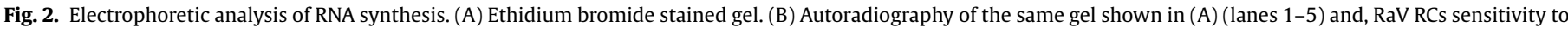

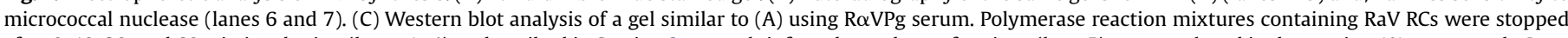

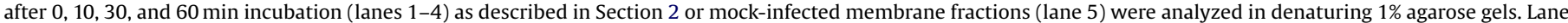

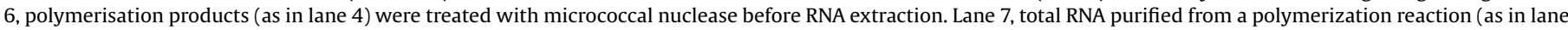
4) and then treated with nuclease in the same conditions as reaction in lane 6 . The sizes of the RNA molecular size markers are indicated in kb.

RNA products purified and analysed in $1.0 \%$ agarose-formaldehyde denaturing gels as described in Section 2. Direct visualisation of RNA after ethidium bromide staining of the gels is shown in Fig. 2A. Radiography of the gels revealed label incorporation into two major RNA products of about 8.5 and $3.0 \mathrm{~kb}$ (Fig. 2B, lanes 1-4). In contrast, no radiolabelled RNA bands were detected after 60 min using a similar P14500 fraction from mock-infected cells (Fig. 2B, lane 5) demonstrating that the 8.5 and $3.0 \mathrm{~kb}$ bands were of viral origin. Interestingly, these RNAs were of the expected size for RaV genomic (gRNA) and subgenomic (sgRNA) species (MartinAlonso et al., 2005) and increased in label intensity with the incubation time (Fig. 2B compare lanes 1 and 4). No radiolabelled products were observed after $120 \mathrm{~min}$ reaction in the presence of $\left[\alpha^{32} \mathrm{P}\right]$ UTP but omitting the remaining three NTPs indicating that the observed labelled bands were not due to terminal transferase activity (data not shown). These results demonstrate that the isolated membranous P14500 fraction contained active RaV RCs.

Aiming to investigate if the virus replication machinery within the RCs could be used to replicate externally added templates, nuclease micrococcal treatments were performed in order to deplete endogenous RNAs. The treatments were not able to degrade the radiolabelled RaV RC-associated RNAs indicating that they were located within an RNase-protected environment (Fig. 2B, lane 6). Total RNA purified from a polymerization reaction using the RNeasy kit and then treated with nuclease in the same conditions as above was completely degraded (Fig. 2B, lane 7) indicating that the micrococcal nuclease was functional. Synthetic transcripts of positive polarity, derived from the RaV genome 3 '-end, smaller in size than the sgRNA were also used. This was done in order to investigate the accessibility of such transcripts to the RaV replication machinery within RCs in such a way that their derived products could be distinguishable by size from the native viral RNAs. After repeated attempts, no distinct labelled products, other than the ones observed in the absence of added transcripts were detected (data not shown).

To further analyze the RNA content of RaV RCs qRT-PCR assays were designed to specifically detect positive gRNA and sgRNA molecules as well as negative sense gRNA (see Section 2). The results (Table 2 ) indicated that purified RCs contained a posi- tive strand sgRNA/gRNA ratio of 3.6 whereas the relative ratio of (+)gRNA/(-)gRNA was 26. Similar qRT-PCR analyses were performed on RNA extracted from purified RaV virions showing a $(+) \operatorname{sgRNA} /(+)$ gRNA relative ratio of 3.3 . However, the ratio of $(+)$ gRNA/(-)gRNA in the virions was 173 , indicating a selective packaging of the $(+)$ gRNA into virions. The lower $(+)$ gRNA/(-)gRNA ratio found in $R C s$ with respect to $R a V$ virions was mainly due to the higher (-) gRNA levels found in the RCs (Table 2) reflecting their role as virus replication factories.

In order to investigate the presence of the genome linked protein (VPg) and its role in RaV genome replication a gel, similar to that shown in Fig. 2A, was transferred to a Duralose-UV membrane and incubated with a specific rabbit anti-RaV VPg serum. The resulting Western blot analysis (Fig. 2C) showed two reactive bands with electrophoretic mobility similar to those of the labelled genomic and subgenomic RaV RNAs suggesting that at least a fraction of the gRNA and sgRNAs within the RCs was linked to VPg. However, it should be mentioned that a significant increase in the amount of immunoreactive VPg associated to RaV RNAs was not detected at longer incubation times by Western blot analysis (Fig. 2C, compare lanes 1 and 4).

RaV RCs were also used to investigate uridylylation of endogenous VPg (Fig. 3A) as described in Section 2. The incubation of purified RCs from RaV-infected cells in the presence of $\left[\alpha-{ }^{32} \mathrm{P}\right]-$ UTP under appropriate conditions yielded a major radio labelled protein band of about $19 \mathrm{kDa}$ (Fig. 3A, lane 2), slightly larger in size than the calculated $12.4 \mathrm{kDa}$ for RaV VPg. Nevertheless this band was similar in size to the antigen detected in RaV RCs by Western blot (Fig. 3B, lane 2) using specific anti-VPg antibodies. This labelled $19 \mathrm{kDa}$ protein was absent in a similar membrane fraction purified from mock-infected cells (Fig. 3A, lane 1). It should be mentioned that several higher Mr labelled bands could be also observed in both mock and RaV-derived RCs (Fig. 3A, lanes 1 and 2) possibly representing unspecific non-virus related products. Nevertheless, considering that $3 \mathrm{AB}$ (VPg-precursor) will run in this kind of gel slightly above the $45 \mathrm{kDa}$ marker (see Fig. 3B, lane 2), a weakly labelled band of $45 \mathrm{kDa}$ (Fig. 3A, lane 2) could also represent an uridylylated form of this precursor. To support or reject this last hypothesis, the relative amounts of VPg and its $3 \mathrm{AB}$ precursor were investigated by Western blot in mock or RaV-derived RCs, using a

Table 2

RNA quantification in RaV virions and RCs using qRT-PCR

\begin{tabular}{|c|c|c|c|c|c|}
\hline Sample & $(+) g_{R N A}^{a}$ & $(+) \operatorname{sgRNA}^{a}$ & $(-)$ gRNA $^{a}$ & $(+) \operatorname{sg} /(+) g$ RNA & $(+) g /(-) g$ RNA \\
\hline $\mathrm{RCs}$ & $85 \pm 2.8$ & $299.88 \pm 2.2$ & $3.27 \pm 0.16$ & 3.6 & 26 \\
\hline Virions & $90.2 \pm 2.1$ & $297.8 \pm 1.9$ & $0.521 \pm 0.03$ & 3.3 & 173.12 \\
\hline
\end{tabular}

\footnotetext{
a Quantities (ng) corresponded to mean values \pm S.D. from three experiments.
} 

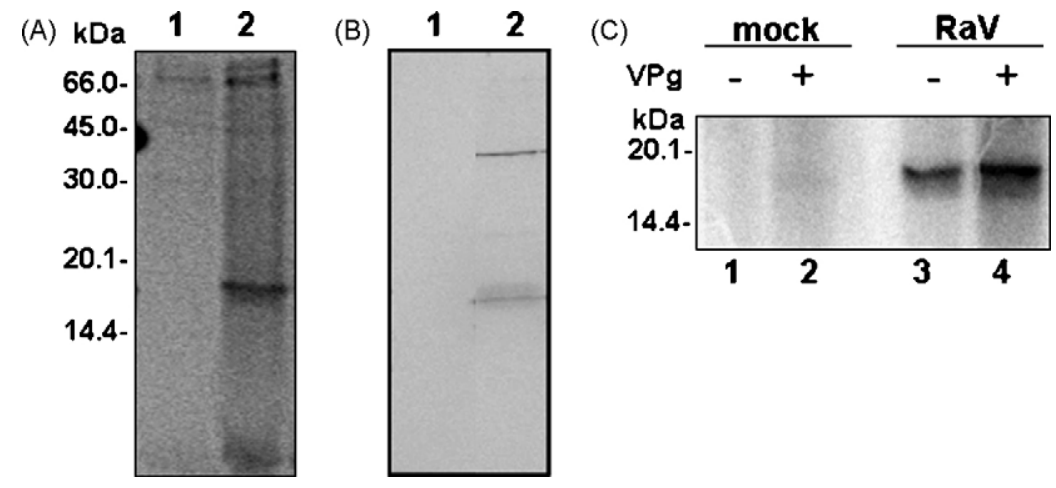

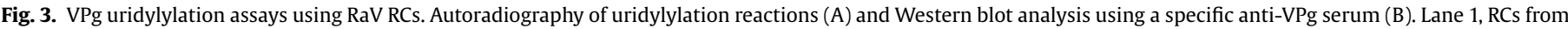

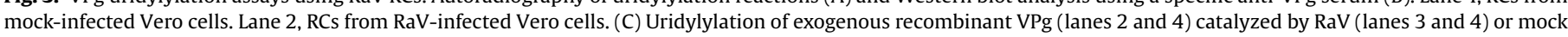
infected (lanes 1 and 2) RCs.

specific rabbit anti-VPg serum (Fig. 3B). The data indicated that the $3 \mathrm{AB}$ precursor can be efficiently detected in the RCs as well as its derivative VPg (Fig. 3B, lane 2), whose detection required longer incubation periods with the substrate and sometimes could not be detected, presumably because its concentration was below the detection levels of the Western blot assay used. Neither 3AB nor VPg were detected in RCs derived from mock-infected cells (Fig. 3B, lane 1).

Uridylylation of exogenous recombinant VPg added to the RCs was also investigated. Recombinant $\mathrm{VPg}(1.4 \mu \mathrm{g})$ added to the reaction (Fig. 3C) seems to be accessible to the uridylylation machinery in the RaV RCs membranous preparation (Fig. 3C, lane 4). Quantification of the amount of $\left[\alpha{ }^{32} \mathrm{P}\right]$-UMP incorporated into the reaction products revealed that 1.85 times more labelled VPg was observed when the recombinant protein was added (Fig. 3C, lane 4) compared to the amount observed when it was not added (Fig. 3C, lane 3 ). This figure was the mean result of three independent experiments. No bands corresponding to uridylylated VPg were observed in reactions with mock RCs added with or without exogenous VPg (Fig. 3C, lanes 1 and 2, respectively).

\subsection{Structural characterization of RaV RCS}

The identity of the viral proteins associated with RaV RCs at 4 hpi was investigated by Western blot analysis using a battery of rabbit polyclonal antisera $(R \alpha)$ raised against several predicted mature RaV products (Fig. 4A). According to the previously published putative RaV processing map (Martin-Alonso et al., 2005), based on the substrate specificity found for calicivirus 3C-like protease (Wirblich et al., 1995), the estimated molecular masses for RaV non-structural and structural proteins would be $31.7 \mathrm{kDa}(2 \mathrm{AB})$, $39.1 \mathrm{kDa}$ (putative NTPase 2C), $30.7 \mathrm{kDa}(3 \mathrm{~A}), 12.4 \mathrm{kDa}$ (3B, genome linked protein $\mathrm{VPg}$ ), $76.6 \mathrm{kDa}$ (bifunctional protease-polymerase, $3 \mathrm{CD}$ ) and $60.8 \mathrm{kDa}$ (mature capsid protein, mCap). The Western blots using specific R $\alpha 2 A B$ serum revealed the presence of a singlespecific reacting polypeptide of about $33 \mathrm{kDa}$ (Fig. 4B, panel $\mathrm{R} \alpha 2 \mathrm{AB}$ )

(A)
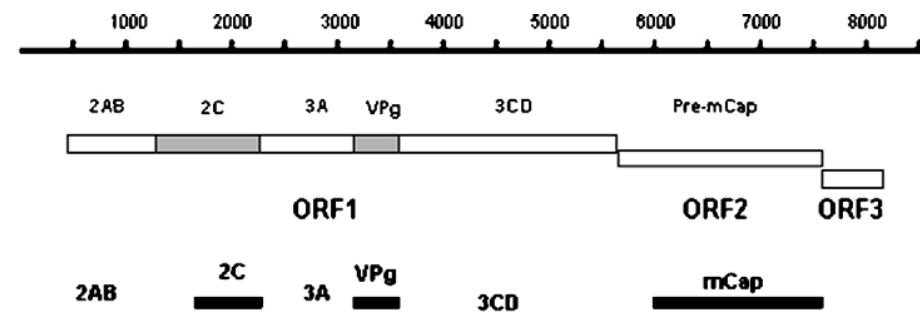

(B)
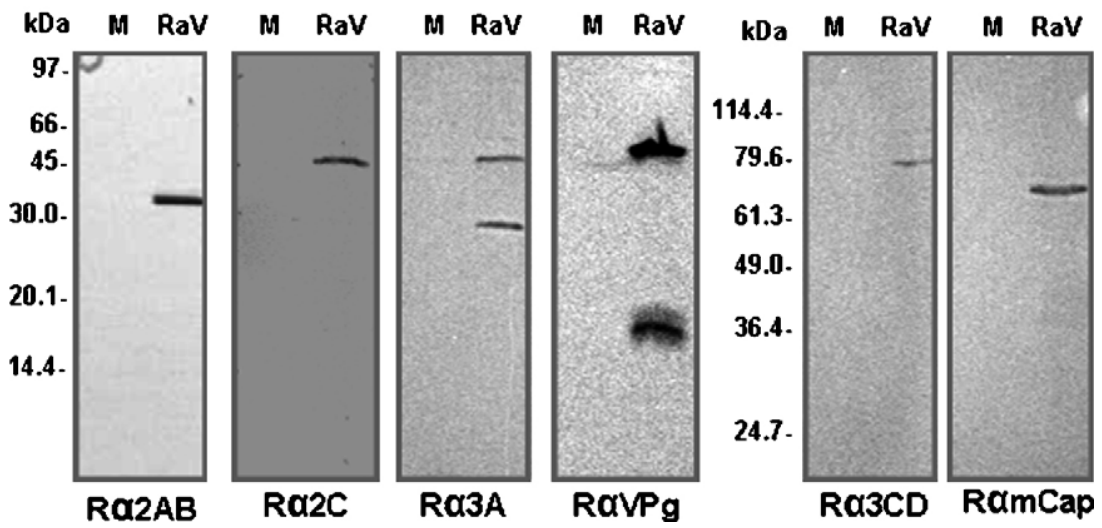

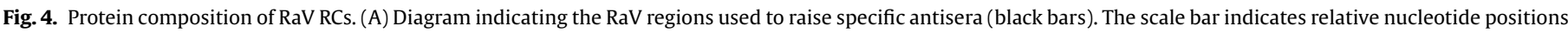

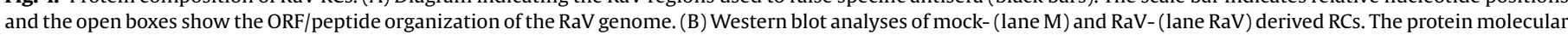
weigh markers are indicated in $\mathrm{kDa}$. 
similar to that expected for $2 \mathrm{AB}$. This result further indicated that no processing of this region into $2 \mathrm{~A}$ and $2 \mathrm{~B}$ occurred at this time of infection. Rabbit anti-2C polyclonal serum identified a protein band of about $43 \mathrm{kDa}$ (Fig. 4B, panel R $\alpha 2 \mathrm{C}$ ), slightly larger than the calculated $(39.1 \mathrm{kDa}$ ) for $2 \mathrm{C}$ protein. R $\alpha 3 \mathrm{~A}$ identified two specific protein products of about 48 and $29 \mathrm{kDa}$ (Fig. $4 \mathrm{~B}$, panel $\mathrm{R} \alpha 3 \mathrm{~A}$ ), which could correspond to precursor $3 \mathrm{AB}$ and mature $3 \mathrm{~A}$ product respectively. Rabbit anti-VPg identified two bands of 48 and $19 \mathrm{kDa}$, respectively (Fig. 4B, panel R $\alpha \mathrm{VPg}$ ), which could correspond to precursor $3 \mathrm{AB}$ (also identified by $\mathrm{R} \alpha 3 \mathrm{~A}$ ) and mature product $3 \mathrm{~B}$ (VPg). It should be mentioned that VPg in the crude membrane extracts consistently migrated as a broad band in $15 \%$ polyacrylamide gels with an apparent molecular mass of about $19 \mathrm{kDa}$ larger than the calculated $12.4 \mathrm{kDa}$. R $\alpha 3 \mathrm{CD}$ identified a protein of $78 \mathrm{kDa}$ (Fig. 4B, panel R $\alpha 3 C D$ ), which could correspond to RaV 3CD with a calculated molecular mass of $76.6 \mathrm{kDa}$. We have also investigated if the mature structural protein (mCap) was present in the RCs. The results using R $\alpha$ mCap serum detected a unique $65 \mathrm{kDa}$ protein band (Fig. 4B, R $\alpha$ mCap panel), identical to the mCap present in RaV purified virions, migrating slower than expected for the calculated $60.8 \mathrm{kDa}$. None of the RaV proteins detected in RaV-infected RCs were present in mock-infected membrane fractions (Fig. 4B, lanes $\mathrm{M}$ ). Pre-immune sera did not react with any protein present in mock- or RaV-infected cells (data not shown). Our data indicated that all the studied $\mathrm{RaV}$ proteins $2 \mathrm{AB}, 2 \mathrm{C}, 3 \mathrm{~A}, 3 \mathrm{~B}, 3 \mathrm{CD}$ and mCap were present in the purified membrane fractions (RCs) from RaV-infected cells.

The subcellular distribution of the viral non-structural and structural proteins present in the RaV RCs was investigated by immunofluorescence (IF) microscopy using rabbit polyclonal sera raised against the predicted mature RaV products (Fig. 4A). The IF results indicated that the non-structural proteins $2 \mathrm{C}, 3 \mathrm{~A}, \mathrm{VPg}$ and $3 \mathrm{CD}$ (Fig. 5A), and 2AB (Fig. 5B), were found in the cytoplasm of RaVinfected cells showing a granular pattern of bright fluorescent dots in the perinuclear region, whose shape and size varied between non-structural proteins and from cell to cell, suggesting the formation of RCs. This distribution pattern was similar to that found for calnexin (Fig. 5B, calnexin), a calcium-binding, type I integral membrane protein that localized primarily in the endoplasmic reticulum (ER). Double-label immunofluorescence experiments showed colocalization of the protein $2 \mathrm{AB}$ and calnexin (Fig. 5B) in dense spots on the perinuclear ER membranes. Similar co-localization results were obtained using specific antibodies against 2C, $3 \mathrm{~A}, \mathrm{VPg}$ and $3 \mathrm{CD}$ (not shown). In contrast to that found for the non-structural proteins, the structural protein mCap was evenly distributed in the cellular cytoplasm (Fig. 5A, mCap).

Given the similar subcellular distribution pattern of the non-structural proteins we investigated the co-localization and membrane association of RaV proteins, viral RNA and calnexin, in the crude membrane fraction (P14500) using linear sucrosegradients (10-50\%). After centrifugation 9 fractions were manually collected from top to bottom of the gradient and the sediment suspended in a similar volume of isotonic buffer. Aliquots of each gradient fraction and the sediment (Fig. 6, lanes P) were used to investigate the presence of calnexin and RaV proteins by Western blot or RaV RNA by dot-blot analyses. ER-resident protein calnexin, the non-structural proteins $2 \mathrm{AB}, 2 \mathrm{C}, 3 \mathrm{~A}, 3 \mathrm{CD}$ and $\mathrm{VPg}$ and the viral RNA (Fig. 6) were detected mainly in fractions 7,8 and 9, at high sucrose densities. In contrast, the structural protein mCap, which we would expect to be in part a soluble not
(A)

$2 \mathrm{C}$

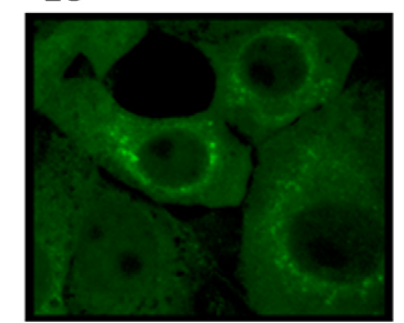

$3 C D$

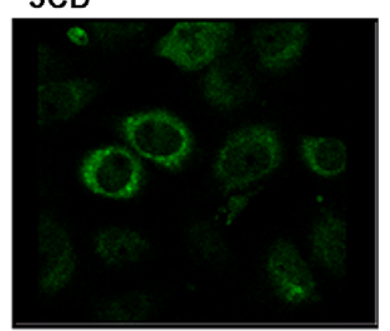

$2 A B$

(B)

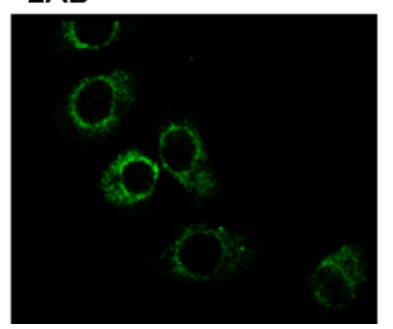

$3 A$

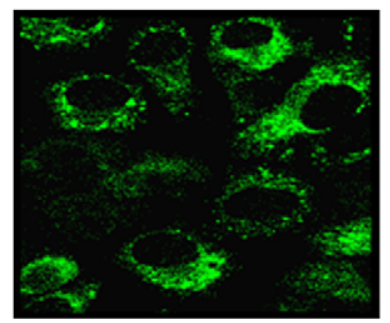

mCap

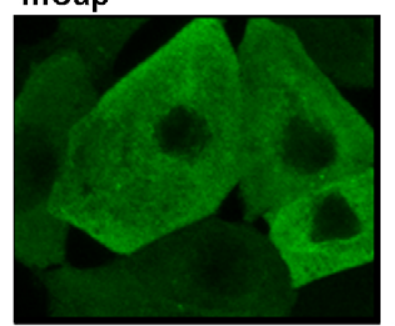

Calnexin

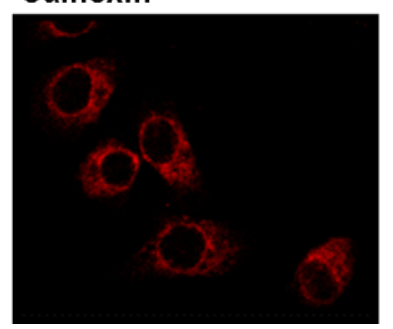

VPg

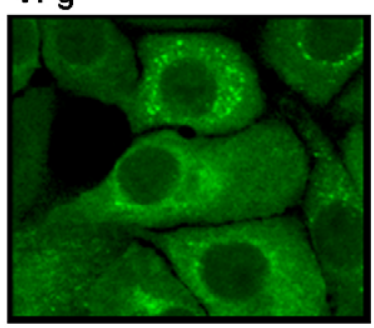

mock

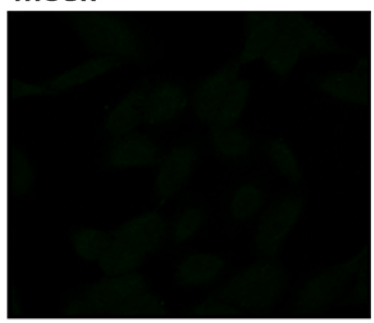

Merge

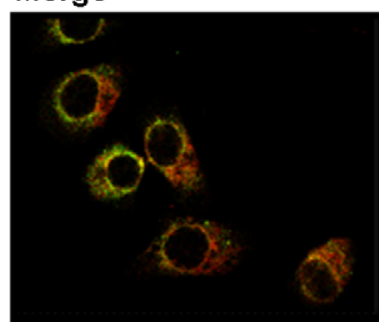

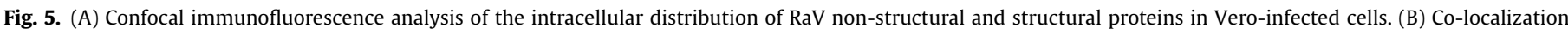

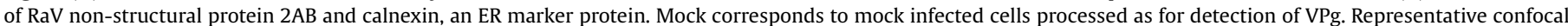
images are shown. Scale bar, $20 \mu \mathrm{m}$. 
Wo NP-40

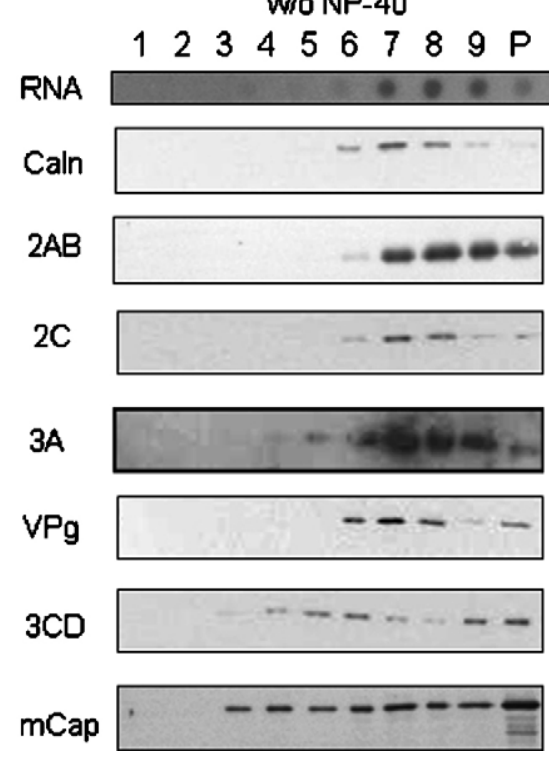

with NP-40
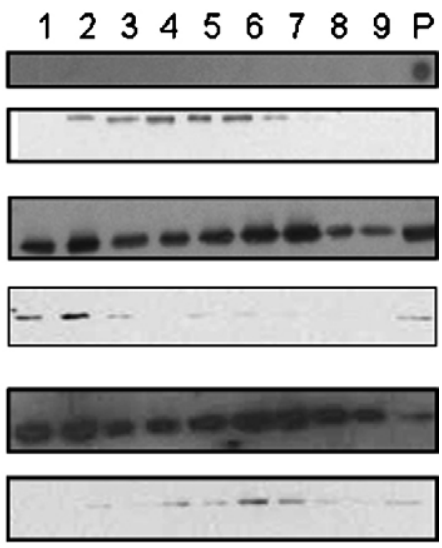

$-\overline{-}$

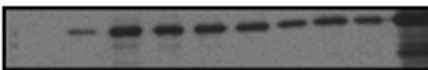

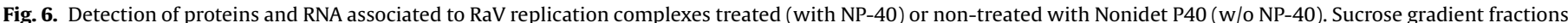

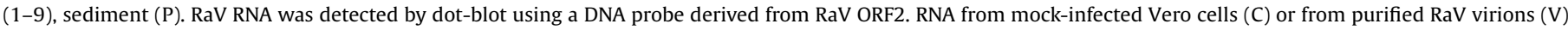

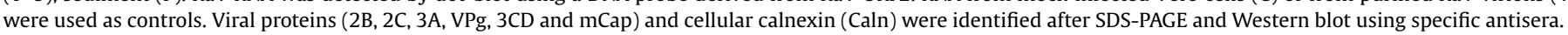

membrane-associated protein, was found in fractions 3-5 (Fig. 6) in addition to higher sucrose density fractions (7-10). These results suggested that RaV-induced membranes cofractionated with ER protein marker calnexin indicating that RCs were of membranous nature and that this organelle could be one of the membrane sources for construction of RaV replication complexes.

To investigate the membranous nature of the structures sedimenting in fractions 7-9 of the above described sucrose gradient, the RC containing P14500 was previously treated on ice with $1 \%$ $\mathrm{NP}-40$ for $1 \mathrm{~h}$ and then layered on top of a similar sucrose gradient. The detergent treatment drastically modified the calnexin distribution to low density fractions (2-6) indicating the solubilisation of this ER marker protein (Fig. 6 with NP-40, Caln). A similarly modified gradient pattern was found for the non-structural RaV proteins $2 \mathrm{AB}, 2 \mathrm{C}, 3 \mathrm{~A}, 3 \mathrm{CD}$ and VPg after treatment with NP-40 (Fig. 6 with NP-40, 2AB, 2C, 3A, 3CD and VPg). RaV genome also modified its distribution now migrating to the gradient sediments (Fig. 6 with NP-40 RNA, lane P) as expected for non membrane-associated free RNA. In contrast, no change of distribution was observed for the structural protein mCap. Unfortunately, although it is clear that the presence of NP-40 caused a general modification of the gradient protein distribution, the detergent treatment was not $100 \%$ efficient for $2 \mathrm{AB}, 3 \mathrm{~A}$ and $\mathrm{VPg}$, as a small quantity of these proteins remained in the original fractions. These results supported that the RaV RCs are membrane associated.

\section{Discussion}

The molecular mechanisms of calicivirus RNA replication have not been studied in as much detail as in other positive-strand RNA viruses mainly due to the lack, for most of them, of an efficient cell culture system and to the difficulties found for producing infectious clones (Chang et al., 2005; Chaudhry et al., 2007; Sosnovtsev and Green, 1995) that could be used for such molecular studies. The investigation of enzyme reactions relevant to virus replication, such as RNA synthesis initiation and elongation or the role of VPg in genome replication, which have been extensively studied in the poliovirus system using in vitro cell free systems (Cello et al., 2002;
Franco et al., 2005; Molla et al., 1991) have been mostly addressed in caliciviruses using recombinant proteins in vitro (López Vázquez et al., 1998; Machín et al., 2001; Marin et al., 2000; Morales et al., 2004), in the absence of other viral and cellular components which might be crucial for the specificity and efficiency of such processes. The isolation of replication complexes from virus-infected cells could provide a valuable tool for studying, not only the macromolecular components involved in such membranous structures but as an experimental system in which various parameters and or components could be accessible to external manipulation. A previous study on FCV (Green et al., 2002) demonstrated that isolated RCs were able to synthesize viral RNA in vitro and contained nearly all virus-encoded proteins.

Aiming to develop an in vitro system to investigate RaV replication mechanisms we have purified RCs from Vero-infected cells and found that these cell-free membranous structures were able to incorporate NTPs into two major RNA species, similar in size to the viral gRNA and sgRNA (Fig. 2B) even in the absence of an ATP regenerating system used in a previous study of FCV RCs (Green et al., 2002). Nevertheless our data do not allow us to conclude whether the RCs were initiating the synthesis of new RNA strands or they were just elongating existing incomplete molecules already initiated at the time of harvest. The results shown in Fig. $2 \mathrm{C}$ indicating that all, or a portion of the two major viral RNA species present in the RCs, were linked to VPg and that the amount of this genomic protein did not increase with time of reaction (Fig. 2C, compare lanes 1 and 4) suggest that there was not newly synthesized RNA strands initiated from free VPg in vitro but it is also possible that the amount of newly-synthesized molecules represented a very small fraction of the total, and therefore an increase in RNA-linked VPg was not detected by Western blot. It could be also argued that Western blot analyses are not sensitive enough to quantify small increases in RNA-linked VPg concentration in the replication complexes whereas radioactivity incorporation more sensitively detects small increases in RNA synthesis.

The viral RNA content of purified RCs was investigated using qRT-PCR analyses indicating that (+)sgRNA was more abundant than (+)gRNA. This fact reveals that sgRNA synthesis is a relatively early event in $\mathrm{RaV}$ replication and that its accumulation in excess 
to gRNA could be due to its smaller size that would allow its faster production. These high levels of sgRNA could be required to allow the synthesis of high concentrations of the major capsid component. The elevated sgRNA concentration within RCs also offers an explanation as to the packaging of this RNA species into separate particles of lower density that has been reported for RHDV (Meyers et al., 1991) and for FCV (Neill, 2002). The biological role of this separate or joint packaging of sgRNA into virions is uncertain, as the infectious calicivirus clones described up to now are viable starting the virus cycle from gRNA only (Chang et al., 2005; Chaudhry et al., 2007; Sosnovtsev and Green, 1995). Nevertheless the presence of pre-made sgRNA at the time of infection could contribute to the efficiency of virus replication and points out the relevance of early capsid protein synthesis in the calicivirus systems. The qRT-PCR also shows that $(-)$ gRNA is about seven times more abundant in the RaV RCs than in the virions, reflecting their different biological functions.

With the aim of studying if RCs could be depleted of their endogenous RNAs and further used to investigate the replication of synthetic templates we treated these membranous structures with micrococcal nuclease. After repeated attempts we have found that the endogenous viral template RNAs were completely protected from nuclease degradation (Fig. 2B, lane 6). Moreover the possibility of using exogenous templates by the RCs viral machinery was also ruled out as no added templates could be polymerized (data not shown) indicating that the RCs harvested at 4 hpi were not accessible for external RNAs. The use of non-ionic detergents to increase RCs permeability to RNA resulted in the loss of polymerase activity on the endogenous templates (data not shown), revealing that this sub-cellular fraction was not amenable to external manipulation, concerning their RNA contents.

Membrane association of RNA replication is an important characteristic of all known positive-stranded RNA viruses (Egger et al., 2000, 2002; El-Hage and Luo, 2003; Froshauer et al., 1988; Gosert et al., 2003; Schwartz et al., 2002; Shi et al., 2003; Suhy et al., 2000; Westaway et al., 1997). In our study, zonal centrifugation fractionation revealed the co-localization of all the $\mathrm{RaV}$ non-structural proteins studied with viral RNA and calnexin, in high sucrose density fractions. This behaviour revealed the putative association of these RNA and protein complexes with the ER or membranes derived from the ER. In agreement with this hypothesis, treatment of the RaV RCs with a non-ionic detergent prior to the fractionation produced significant changes in the distribution of the non-structural proteins towards lower sucrose density fractions and of the RNA to the tube sediment, consistent with their release from the membranous RCs. These results do not exclude the possibility that membranes from other cellular organelles (golgi complex and lysosomes) are part of the RCs as it has been shown for poliovirus (Schlegel et al., 1996). Previous studies (Fogg et al., 2003) showed that intact membranes in the RCs are required for initiation and elongation of poliovirus RNA synthesis in HeLa cell extracts.

Our studies aiming to identify the viral protein components present in the purified RCs revealed that all investigated viral products (2C, 3A, 3B and the major capsid component) were present as mature proteins and no precursors other than $3 A B$ and $3 C D$ could be detected. $2 \mathrm{AB}$ and $3 \mathrm{CD}$, which in other calicivirus systems are processed into mature products were not further processed in RaVinfected cells and consequently should not be considered as true precursors. The data also indicated that RaV RCs contained VPg (3B-like) linked to genomic and subgenomic RaV RNAs (Fig. 2C). This protein was also found in a free state, not linked to RNA, as has been shown for other viral systems (Takegami et al., 1983). The existence of free VPg within the RCs could be demonstrated by its ability to become uridylylated in the presence of radioactive UTP
(Fig. 3). From our data it is difficult to draw conclusions concerning the putative uridylylation of the $3 \mathrm{AB}$ precursor. Even though the Western blot (3B and $5 \mathrm{~B}$ ) indicated that $3 \mathrm{AB}$ was more abundant than free VPg in the RaV RCs it could be that uridylylation of $3 \mathrm{AB}$ was a less efficient process and consequently could not be detected in our experimental system (Fig. 3A, lane 2). In contrast uridylylation of both VPg and its precursor has been reported for poliovirus (Takegami et al., 1983). Interestingly, exogenous recombinant VPg added to the RCs seems to be accessible to the uridilylation machinery of the RCs membranous preparation (Fig. 3C). Considering that the exogenous RNA templates added to the RCs seem not to be accessible to the RaV RdRP within the membranous structures this would reveal either a higher protein permeability of the RCs or the presence of different RdRP topology requirements for polymerization or uridylylation, respectively. It should be mentioned that elongation of the RNA chain starting from nucleotidylylated VPg could not be detected in our studies in agreement with other reports regarding a different calicivirus, using in vitro analyses (Belliot et al., 2008). This might be a significant finding considering the complex structures used in our studies which contain most if not all the required viral and cellular components to complete viral replication. Whether VPg is a true protein primer from which the viral RNA is extended, as has been demonstrated in poliovirus, or this protein ends up linked to the gRNA and sgRNA by a kind of protein capping mechanism in the final steps of genome replication is an intriguing question for which no experimental answers are so far available.

With regard to the organization of the RCs, the non-structural proteins detected in immunofluorescence assays displayed similar patterns of localization in discrete cytoplasmic and perinuclear spots, which in the case of $2 \mathrm{AB}$ colocalise with ER marker calnexin, suggesting that these proteins may form membrane-associated multiprotein cytoplasmic complexes where RNA replication occurs as has been shown for hepatitis C virus (HCV) (El-Hage and Luo, 2003) and by analogy with other positive-stranded RNA viruses (Hwang et al., 1997; Reed and Rice, 2000; Schwartz et al., 2002). In contrast, mCap, showed a very different labelling pattern, it was evenly distributed in the cellular cytoplasm suggesting that it does not play a role in the formation of the cytoplasmic scaffolding where viral replication takes place.

The possibility of using RCs will be a valuable tool for future studies of the requirements of calicivirus replication as well as a good in vitro assay system in which putative antiviral compounds could be analyzed.

\section{Acknowledgments}

Rosa Casais and Jose Manuel Martín-Alonso are recipients of "Ramón y Cajal" contracts from the Spanish Ministerio de Educación y Ciencia cofinanced by Fondo Social Europeo. Alberto García Manso is recipient of a FPI fellowship from the Spanish Ministerio de Educación y Ciencia. This research has been supported by Grant BIO2006-00827 from the Spanish Ministerio de Educación y Ciencia, cofinanced by Fondo Europeo de Desarrollo Regional (FEDER) and Ayuntamiento de Gijón. Prototype RaV was provided by the Laboratory for Calicivirus Studies in collaboration with Alvin W. Smith.

\section{References}

Belliot, G., Sosnovtsev, S.V., Chang, K.O., Babu, V., Uche, U., Arnold, J.J., Cameron, C.E., Green, K.Y., 2005. Norovirus proteinase-polymerase and polymerase are both active forms of RNA-dependent RNA polymerase. J. Virol. 79, 2393-2403.

Belliot, G., Sosnovtsev, S.V., Chang, K.O., McPhie, P., Green, K.Y., 2008. Nucleotidylylation of the VPg protein of a human norovirus by its proteinase-polymerase precursor protein. Virology 374, 33-49. 
Bienz, K., Egger, D., Pfister, T., Troxler, M., 1992. Structural and functional characterization of the poliovirus replication complex. J. Virol. 66, 2740-2747.

Cello, J., Paul, A.V., Wimmer, E., 2002. Chemical synthesis of poliovirus cDNA: generation of infectious virus in the absence of natural template. Science 297, 1016-1018.

Chang, K.O., Sosnovtsev, S.S., Belliot, G., Wang, Q., Saif, L.J., Green, K.Y., 2005. Reverse genetics system for porcine enteric calicivirus, a prototype sapovirus in the Caliciviridae. J. Virol. 79, 1409-1416.

Chaudhry, Y., Skinner, M.A., Goodfellow, I.G., 2007. Recovery of genetically defined murine norovirus in tissue culture by using a fowlpox virus expressing T7 RNA polymerase. J. Gen. Virol. 88, 2091-2100.

Clarke, I.N., Lambden, P.R., 1997. The molecular biology of caliciviruses. J. Gen. Virol 78 (Pt 2), 291-301.

Egger, D., Teterina, N., Ehrenfeld, E., Bienz, K., 2000. Formation of the poliovirus replication complex requires coupled viral translation, vesicle production, and viral RNA synthesis. J. Virol. 74, 6570-6580.

Egger, D., Wolk, B., Gosert, R., Bianchi, L., Blum, H.E., Moradpour, D., Bienz, K., 2002 Expression of hepatitis $C$ virus proteins induces distinct membrane alterations including a candidate viral replication complex. J. Virol. 76, 5974-5984.

El-Hage, N., Luo, G., 2003. Replication of hepatitis C virus RNA occurs in a membranebound replication complex containing nonstructural viral protins and RNA. J. Gen. Virol. 84, 2761-2769.

Fogg, M.H., Teterina, N.L., Ehrenfeld, E., 2003. Membrane requirements for uridylylation of the poliovirus VPg protein and viral RNA synthesis in vitro. J. Virol. 77, 11408-11416.

Franco, D., Pathak, H.B., Cameron, C.E., Rombaut, B., Wimmer, E., Paul, A.V., 2005 Stimulation of poliovirus synthesis in a HeLa cell-free in vitro translation-RNA replication system by viral protein $3 \mathrm{CD}$ (pro). J. Virol. 79, 6358-6367.

Froshauer, S., Kartenbeck, J., Helenius, A., 1988. Alphavirus RNA replicase is located on the cytoplasmic surface of endosomes and lysosomes. J. Cell Biol. 107, 2075-2086.

Glass, P.J., White, L.J., Ball, J.M., Leparc-Goffart, I., Hardy, M.E., Estes, M.K., 2000. Norwalk virus open reading frame 3 encodes a minor structural protein. J. Virol. 74 6581-6591.

Gosert, R., Egger, D., Lohmann, V., Bartenschlager, R., Blum, H.E., Bienz, K., Moradpour D., 2003. Identification of the hepatitis $C$ virus RNA replication complex in Huh-7 cells harboring subgenomic replicons. J. Virol. 77, 5487-5492.

Gosert, R., Kanjanahaluethai, A., Egger, D., Bienz, K., Baker, S.C., 2002. RNA replication of mouse hepatitis virus takes place at double-membrane vesicles. J. Virol. 76 3697-3708.

Green, K.Y., 2007. Caliciviridae: The Noroviruses. In: Knipe, D.M., Howley, P.M. (Eds.) Field's Virology. Lippincott Williams \& Wilkins, Philadelphia, pp. 949-979.

Green, K.Y., Mory, A., Fogg, M.H., Weisberg, A., Belliot, G., Wagner, M., Mitra, T. Ehrenfeld, E., Cameron, C.E., Sosnovtsev, S.V., 2002. Isolation of enzymatically active replication complexes from feline calicivirus-infected cells. J. Virol. 76, 8582-8595.

Herbert, T.P., Brierley, I., Brown, T.D., 1996. Detection of the ORF3 polypeptide of feline calicivirus in infected cells and evidence for its expression from a single, functionally bicistronic, subgenomic mRNA. J. Gen. Virol. 77 (Pt 1), 123-127.

Hwang, S.B., Park, K.J., Kim, Y.S., Sung, Y.C., Lai, M.M., 1997. Hepatitis C virus NS5B protein is a membrane-associated phosphoprotein with a predominantly perinuclear localization. Virology 227, 439-446.

Kaiser, W.J., Chaudhry, Y., Sosnovtsev, S.V., Goodfellow, I.G., 2006. Analysis of proteinprotein interactions in the feline calicivirus replication complex. J. Gen. Virol. 87, 363-368.

Laemmli, U.K., 1970. Cleavage of structural proteins during the assembly of the head of bacteriophage T4. Nature 227, 680-685.

López Vázquez, A., Martin Alonso, J.M., Casais, R., Boga, J.A., Parra, F., 1998. Expression of enzymatically active rabbit hemorrhagic disease virus RNA-dependent RNA polymerase in Escherichia coli. J. Virol. 72, 2999-3004.

Machín, A., Martin Alonso, J.M., Parra, F., 2001. Identification of the amino acid residue involved in rabbit hemorrhagic disease virus VPg uridylylation. J. Biol. Chem. 276, 27787-27792.

Marin, M.S., Casais, R., Alonso, J.M., Parra, F., 2000. ATP binding and ATPase activities associated with recombinant rabbit hemorrhagic disease virus 2C-like polypeptide. J. Virol. 74, 10846-10851.
Martin-Alonso, J.M., Skilling, D.E., Gonzalez-Molleda, L., del, B.G., Machin, A., Keefer, N.K., Matson, D.O., Iversen, P.L., Smith, A.W., Parra, F., 2005. Isolation and characterization of a new Vesivirus from rabbits. Virology 337, 373-383.

Meyers, G., Wirblich, C., Thiel, H.J., 1991. Genomic and subgenomic RNAs of rabbit hemorrhagic disease virus are both protein-linked and packaged into particles. Virology 184, 677-686

Molla, A., Paul, A.V., Wimmer, E., 1991. Cell-free, de novo synthesis of poliovirus. Science 254, 1647-1651.

Morales, M., Barcena, J., Ramirez, M.A., Boga, J.A., Parra, F., Torres, J.M., 2004. Synthesis in vitro of rabbit hemorrhagic disease virus subgenomic RNA by internal initiation on (-)sense genomic RNA: mapping of a subgenomic promoter. J. Biol. Chem. 279, 17013-17018.

Neill, J.D., 2002. The subgenomic RNA of feline calicivirus is packaged into viral particles during infection. Virus Res. 87, 89-93.

Pederson, T., 1999. Movement and localization of RNA in the cell nucleus. FASEB J. 13 (Suppl. 2), S238-S242.

Prentice, E., Jerome, W.G., Yoshimori, T., Mizushima, N., Denison, M.R., 2004. Coronavirus replication complex formation utilizes components of cellular autophagy. J. Biol. Chem. 279, 10136-10141.

Reed, K.E., Rice, C.M., 2000. Overview of hepatitis C virus genome structure, polyprotein processing, and protein properties. Curr. Top. Microbiol. Immunol. 242, 55-84.

Schaad, M.C., Jensen, P.E., Carrington, J.C., 1997. Formation of plant RNA virus replication complexes on membranes: role of an endoplasmic reticulum-targeted viral protein. EMBO J. 16, 4049-4059.

Schlegel, A., Giddings Jr., T.H., Ladinsky, M.S., Kirkegaard, K., 1996. Cellular origin and ultrastructure of membranes induced during poliovirus infection. J. Virol. 70, 6576-6588.

Schwartz, M., Chen, J., Janda, M., Sullivan, M., den, B.J., Ahlquist, P., 2002. A positivestrand RNA virus replication complex parallels form and function of retrovirus capsids. Mol. Cell 9, 505-514.

Shi, S.T., Lee, K.J., Aizaki, H., Hwang, S.B., Lai, M.M., 2003. Hepatitis C virus RNA replication occurs on a detergent-resistant membrane that cofractionates with caveolin-2. J. Virol. 77, 4160-4168.

Sosnovtsev, S., Green, K.Y., 1995. RNA transcripts derived from a cloned full-length copy of the feline calicivirus genome do not require VpG for infectivity. Virology $210,383-390$

Sosnovtsev, S.V., Green, K.Y., 2000. Identification and genomic mapping of the ORF3 and VPg proteins in feline calicivirus virions. Virology 277, 193-203.

Sosnovtseva, S.A., Sosnovtsev, S.V., Green, K.Y., 1999. Mapping of the feline calicivirus proteinase responsible for autocatalytic processing of the nonstructural polyprotein and identification of a stable proteinase-polymerase precursor protein. J. Virol. 73, 6626-6633.

Suhy, D.A., Giddings Jr., T.H., Kirkegaard, K., 2000. Remodeling the endoplasmic reticulum by poliovirus infection and by individual viral proteins: an autophagy-like origin for virus-induced vesicles. J. Virol. 74, 8953-8965.

Takegami, T., Semler, B.L., Anderson, C.W., Wimmer, E., 1983. Membrane fractions active in poliovirus RNA replication contain VPg precursor polypeptides. Virology $128,33-47$.

Wei, L., Huhn, J.S., Mory, A., Pathak, H.B. Sosnovtsev, S.V., Green, KY, Cameron, C.E. 2001. Proteinase-polymerase precursor as the active form of feline calicivirus RNA-dependent RNA polymerase. J. Virol. 75, 1211-1219.

Westaway, E.G., Khromykh, A.A., Mackenzie, J.M., 1999. Nascent flavivirus RNA colocalized in situ with double-stranded RNA in stable replication complexes. Virology 258, 108-117.

Westaway, E.G., Mackenzie, J.M., Kenney, M.T., Jones, M.K., Khromykh, A.A., 1997. Ultrastructure of Kunjin virus-infected cells: colocalization of NS1 and NS3 with double-stranded RNA, and of NS2B with NS3, in virus-induced membrane structures. J. Virol. 71, 6650-6661.

Wirblich, C., Sibilia, M., Boniotti, M.B., Rossi, C., Thiel, H.J., Meyers, G., 1995. 3Clike protease of rabbit hemorrhagic-disease virus-identification of cleavage sites in the Orf1 polyprotein and analysis of cleavage specificity. J. Virol. 69, 7159-7168.

Wirblich, C., Thiel, H.J., Meyers, G., 1996. Genetic map of the calicivirus rabbit hemorrhagic disease virus as deduced from in vitro translation studies. J. Virol. 70, 7974-7983. 